\title{
UTICAJ DIABETES MELLITUS-A KAO KOMORBIDITETA NA ISHOD REHABILITACIJE PACIJENATA SA MOŽDANIM UDAROM
}

\author{
Marija Đorđević ${ }^{1}$ Ljubica Konstantinović ${ }^{2}$
}

\author{
${ }^{1}$ Medicinski fakultet Univerziteta u Beogradu \\ ${ }^{2}$ Mentor; Klinika za rehabilitaciju "Dr Miroslav Zotović", Medicinski fakultet Univerziteta u Beogradu
}

Sažetak

Zaključak: Diabetes mellitus kao komorbiditet ne utiče značajno na ishod rehabilitacije pacijenata koji su doživeli moždani udar.

Uvod: Iako je poznata činjenica da diabetes mellitus povećava rizik od nastanka moždanog udara preko dva puta, manje je ispitivano da li prisustvo šećerne bolesti utiče na ishod rehabilitacije kod bolesnika koji su doživeli moždani udar.

Cilj: Sagledavanje uticaja diabetes mellitus-a kao komorbiditeta na ishod rehabilitacije bolesnika koji su doživeli moždani udar.

Materijal i metode: Sprovedena je retrospektivna studija analize slučajeva među obolelim od moždanog udara koji su lečeni na Klinici za rehabilitaciju „Dr Miroslav Zotović“. Svi bolesnici su podeljeni u dve grupe: eksperimentalnu, koju čine oboleli od moždanog udara i šećerne bolesti tipa 1 ili tipa 2, i kontrolnu, koju čine oboleli od moždanog udara, ali ne i od šećerne bolesti. Praćen je konačan ishod rehabilitacije u obe grupe bolesnika. Konačan funkcionalni status pacijenata nakon rehabilitacionog tretmana predstavljen je Functional Independence Measure (FIM) skorom.

Rezultati: Ispitivano je ukupno 40 obolelih -20 u eksperimentalnoj i 20 u kontrolnoj grupi. U eksperimentalnoj grupi dobijena je manja razlika između vrednosti skora FIM na kraju i na početku rehabilitacije (p $=0,588$ ), ali nije utvrđena značajna razlika. Između krajnjeg i početnog FIM skora značajno je veća razlika kod obolelih od tipa 2 šećerne bolesti u odnosu na obolele od tipa 1 šećerne bolesti $(p=0,017)$. I komorbiditeti, i komplikacije bili su češći kod pacijenata iz eksperimentalne grupe $(\mathrm{p}=1,000)$, ali bez postojanja značajne razlike.

Ključne reči: rehabilitacija, moždani udar, diabetes mellitus.

\section{Abstract}

Conclusion: Diabetes mellitus as comorbidity does not have significant role in rehabilitation outcomes of patients who survived stroke.

Introduction: Although it is well-known that diabetes mellitus increases risk for stroke for more than a two-fold, it was not extensively explored if the presence of diabetes mellitus has an influence to the rehabilitation outcome in patients who have had a stroke.

The Aim: Evaluating the influence of diabetes mellitus as a comorbidity to rehabilitation outcomes of patients who survived stroke.

Material and methods: Retrospective case-control study was done among patients with previous stroke at the Clinic for Rehabilitation „Dr Miroslav Zotovic“. All patients were divided into two groups: experimental group, composed from patients who had stroke and diabetes mellitus type 1 or type 2 as comorbidity, and control group, containing patients who had stroke, but without diabetes mellitus. Rehabilitation outcomes were observed in both groups of patients. Functional Independence Measure (FIM) score was used for the assessment of the functional status before and after rehabilitation treatment.

Results: Forty patients were included in the study -20 in experimental and 20 in the control group. In the experimental group, non-significant difference between FIM score at the end and FIM score at the begining of rehabilitation treatment was found $(\mathrm{p}=0.588)$. The difference between FIM scores at the end and at the begining was significantly higher in patients with diabetes mellitus type 2 in comparison to the patients with diabetes mellitus type $1(\mathrm{p}=0.017)$. Experimental group, in comparison to the controls, had more comorbidities and complications, but without significant difference.

Key words: rehabilitation, stroke, diabetes mellitus. 


\section{Uvod}

Moždani udar je akutna cerebrovaskularna bolest sa trajnim posledicama. U njegovoj osnovi može biti infarkt mozga, kada govorimo o ishemijskom moždanom udaru, ili krvarenje u parenhim mozga ili subarahnoidalni prostor, što predstavlja hemoragijski moždani udar. $\mathrm{Na}$ mestu fokalne cerebralne lezije smanjeno je dopremanje kiseonika i glukoze. U anaerobnim uslovima povećana je produkcija slobodnih radikala, nastaje oksidativni stres i mitohondrijalna smrt, što sve zajedno dovodi do ćelijske nekroze i nepovratnih neuroloških lezija. Posledica je trajno oštećenje moždanog tkiva, koje se ispoljava u vidu neurološkog deficita [1]. Moždani udar jedan je od vodećih uzroka smrti u svetu, a kod preživelih je najčešći uzrok dugotrajne nesposobnosti i nemogućnosti obavljanja svakodnevnih aktivnosti [2]. Zbog toga je rehabilitacija ovih bolesnika kontinuiran proces u dužem vremenskom periodu, čak i u hroničnoj fazi bolesti, i obuhvata fizičke vežbe, radno-okupacionu terapiju, kao i druge metode čiji je cilj da bolesnik postane u najvećem mogućem stepenu samostalan i sposoban za aktivno učešće u životu zajednice [3]. Međutim, pokazano je da na ishod rehabilitacije može uticati postojanje šećerne bolesti kao komorbiditeta, ali vrlo mali broj istraživanja govori o ovoj temi [4].

Šećerna bolest, predstavlja stanje hronične hiperglikemije, nastalo zbog insuficijencije pankreasa ili insulinske rezistencije. To je kompleksni metabolički sindrom, sa značajnim efektima na sistemsku i cerebralnu vaskulaturu. U razvojnom toku dovodi do endotelne disfunkcije i trofičkih promena malih krvnih sudova, a potom i većih, što dovodi do smanjenja oksigenacije i ishemije tkiva, a oštećenja se ispoljavaju na svim tkivima [5]. Mikrovaskularna oštećenja se patohistološki uočavaju kao hijalinoza sa suženim lumenom intrakranijalnih krvnih sudova. Zbog trofičkih promena na krvnim sudovima, može doći do slabljenja zida krvnog suda, što može biti praćeno hemoragijom, ili do stenoze, subokluzije ili okluzije, koja dovodi do smanjenja cirkulacije u određenom regionu, što dovodi do ishemije. Zbog toga su oboleli od dijabetesa u povećanom riziku za nastanak hipertenzije, koronarne bolesti i moždanog udara [6]. Šećerna bolest povećava rizik od nastanka moždanog udara preko dva puta $[5,6]$. Kod $30-40 \%$ osoba sa preživljenim akutnim ishemijskim moždanim udarom ustanovljena je hiperglikemija, koja može biti prouzrokovana oslobađanjem kataboličkih hormona u toku stresne reakcije, dok poseban problem predstavlja neregulisana hiperglikemija kod šećerne bolesti. Hiperglikemija koja duže traje dovodi do ireverzibilne glikozilacije proteina arterijskog zida, što prouzrokuje okluziju lumena i ishemiju [6].
Diabetes mellitus nije samo nezavisni, fundamentalni faktor rizika za nastanak moždanog udara, već takođe može predstavljati značajnu prepreku i ograničenje procesa rehabilitacije kod obolelih od šećerne bolesti nakon moždanog udara. Neadekvatno kontrolisana šećerna bolest ili neadekvatno spovođenje terapije insulinom, posebno u toku akutnih cerebrovaskularnih komplikacija moždanog udara, mogu povećati površinu ishemijske lezije i rizik od nastanka ponovnog moždanog udara. Kod obolelih od šećerne bolesti, tok moždanog udara je mnogo ozbiljniji, češća je pojava cerebralnog edema, a mortalitet je veći. Iz ovih razloga, čest je i ozbiljan klinički problem postojanje šećerne bolesti kao komorbiditeta u stanjima moždanog udara $[6,7]$.

Cilj rada je sagledavanje uticaja diabetes mellitus-a kao komorbiditeta na ishod rehabilitacije osoba koje su doživele moždani udar.

\section{Materijal i metode}

Sprovedena je retrospektivna studija analize slučajeva (engl. case-control study) među pacijentima obolelim od moždanog udara koji su lečeni na Klinici za rehabilitaciju „Dr Miroslav Zotović“. Podaci su dobijeni iz istorija bolesti.

Svi ispitanici su podeljeni u dve grupe: eksperimentalnu, koju čine oboleli od moždanog udara i šećerne bolesti tipa 1 ili tipa 2, i kontrolnu, koju čine oboleli od moždanog udara, ali ne i od šećerne bolesti. Praćen je tok i konačan ishod rehabilitacije u obe grupe obolelih.

$\mathrm{Za}$ meru konačnog ishoda rehabilitacije uzet je FIM skor (Functional Independence Measure) - mera funkcionalne nezavisnosti pacijenta koja je neophodna za samostalni zivot. Kod svakog ispitanika se testira sposobnost izvođenja zadataka iz oblasti: ishrana, sređivanje, kupanje, oblačenje gornjeg i donjeg dela tela, odlazak u kupatilo, odlazak u toalet i njegovo korišćenje, kontrola uriniranja i defekacije, prelazak iz kreveta na stolicu, korišćenje stepenica, pokretljivost, kognitivno razumevanje, facijalna ekspresija, socijalna interakcija, rešavanje problema, pamćenje. Svaki zadatak ocenjuje se na skali - od broja 7, koji označava potpunu funkcionalnu nezavisnost, do broja 1, koji označava potpunu nesposobnost da se obavi taj zadatak, i gde obavljanje ove radnje iziskuje pomoć druge osobe. Kako ima ukupno 18 zadataka, vrednosti FIM skora mogu iznositi od 18 do 126. Ovaj instrument je značajan za monitoring funkcionalnog oporavka u dužem vremenskom periodu [8]. Samostalno, FIM skor ukazuje na funkcionalni status pacijenta $\mathrm{u}$ tom trenutku, a razlika između vrednosti FIM skora na kraju i vrednosti FIM skora na početku rehabilitacije ukazuje na uspešnost funkcionalnog oporavka pacijenta $\mathrm{u}$ toku rehabilitacionog procesa. 
Dobijeni rezultati analizirani su pomoću programa SPSS, metodama t-test, $\chi^{2}$ test, kao i Fišerovim testom tačne verovatnoće.

\section{Rezultati}

Ispitivano je ukupno 40 bolesnika, 20 u eksperimentalnoj i $20 \mathrm{u}$ kontrolnoj grupi. Među ispitanicima u eksperimentalnoj grupi, četvoro je imalo diabetes mellitus tip 1, a 16 diabetes mellitus tip 2. Godine starosti ispitanika, broj dana proteklih od nastanka insulta do započinjanja hospitalizacije, trajanje hospitalizacije, kao i funkcionalni status na početku i na kraju procesa rehabilitacije, procenjeni FIM skorom, prikazani su u tabeli 1. Razlika između vrednosti FIM skora na početku i na kraju rehabilitacije je značajna $(t=-16,130$; $\mathrm{df}=39,000$; $\mathrm{p}<0,001$ ), odnosno značajno je veći FIM skor na kraju rehabilitacije nego na njenom početku.

Tabela 1. Karakteristike pacijenata uključenih u studiju.

\begin{tabular}{|c|c|c|c|}
\hline & $\begin{array}{c}\text { Eksperimentalna } \\
\text { grupa }\end{array}$ & $\begin{array}{c}\text { Kontrolna } \\
\text { grupa }\end{array}$ & $\begin{array}{c}\text { Svi ispitivani } \\
\text { pacijenti }\end{array}$ \\
\hline Prosečna starost & $67,50 \pm 5,19$ & $66,85 \pm 5,36$ & $67,18 \pm 5,22$ \\
\hline $\begin{array}{l}\text { Br. dana od nastanka insulta do } \\
\text { početka hospitalizacije }\end{array}$ & $16,10 \pm 1,71$ & $14,45 \pm 1,67$ & $15,28 \pm 1,87$ \\
\hline Trajanje hospitalizacije & $55,45 \pm 4,86$ & $52,30 \pm 5,14$ & $53,88 \pm 5,19$ \\
\hline FIM na početku rehabilitacije & $60,15 \pm 4,00$ & $62,50 \pm 4,79$ & $61,33 \pm 4,51$ \\
\hline FIM na kraju rehabilitacije & $73,55 \pm 6,44$ & $76,85 \pm 5,95$ & $75,20 \pm 6,34$ \\
\hline $\begin{array}{l}\text { Razlika FIM na kraju i na } \\
\text { početku rehabilitacije }\end{array}$ & $13,40 \pm 4,29$ & $14,35 \pm 6,48$ & $13,88 \pm 5,44$ \\
\hline
\end{tabular}

${ }^{*}$ srednja vrednost $\pm \mathrm{SD}$

Uočeno je da su oboleli od šećerne bolesti duže bili hospitalizovani $(\mathrm{t}=-1,991 ; \mathrm{df}=38,000 ; \mathrm{p}=0,054)$, imali manju početnu vrednost FIM $(t=1,685 ; \mathrm{df}=$ 38,000; $\mathrm{p}=0,100)$, kao i manju vrednost FIM na kraju procesa rehabilitacije $(\mathrm{t}=1,684 ; \mathrm{df}=38,000 ; \mathrm{p}=0,100)$. Samim tim je kod njih manja razlika između skora FIM na kraju i na početku rehabilitacije nego kod pacijenata koji boluju od šećerne bolesti $(t=0,547$; $\mathrm{df}=32,963$; $\mathrm{p}=0,588$ ), ali nije utvrđena značajna razlika $\mathrm{u}$ odnosu na kontrolnu grupu. Međutim, rezultati pokazuju da je između krajnjeg i početnog FIM skora postojala značajno veća razlika kod obolelih od tipa 2 šećerne bolesti u odnosu na obolele od tipa 1 šećerne bolesti $(\mathrm{t}=-2,630$; $\mathrm{df}$ $=18,000 ; \mathrm{p}=0,017$ ).

Pre početka rehabilitacionog tretmana, kod 28 obolelih (70\%) postojao je komorbiditet, a da to pridruženo oboljenje nije šećerna bolest. Najčešća pridružena oboljenja bila su: hipertenzija (23\% ispitivanih pacijenata), atrijalna fibrilacija (15\%) i hiperlipidemija (29\%). $\mathrm{U}$ toku rehabilitacionog tretmana kod 31 pacijenta (77,5\%) pojavile su se komplikacije osnovnog oboljenja - moždanog udara. Te komplikacije najviše su se javljale u obliku urinarne infekcije (30\%) i depresije (25\%). Udružena oboljenja u većem procentu postojala su u eksperimentalnoj grupi $\left(\chi^{2}=1,905 ; p=1,000\right)$, ali ta razlika nije se pokazala kao značajna. Takođe, i komplikacije su bile češće kod pacijenata iz eksperimentalne grupe, ali ni ovde se razlika nije pokazala značajnom. Češće su se komorbiditet i komplikacije pojavljivali zajedno, kod istih pacijenata, nego pojedinačno, ali, opet, bez značajne razlike $\left(\chi^{2}=0,061 ; p=1,000\right)$.

\section{Diskusija}

Istraživanja koja se bave uticajem šećerne bolesti na obolevanje od moždanog udara pokazuju da je kod obolelih od šećerne bolesti veći rizik od pojave moždanog udara, a potom i od komplikacija, da su češći komorbiditeti i recidivi, sporiji oporavak, da su promene ireverzibilne, a mortalitet veći, posebno na početku hospitalizacije $[6,9,10]$. Posebno težak oblik ispoljavanja moždanog udara javlja se u slučaju neregulisane hiperglikemije u trenutku moždanog udara. Tada je usporena i manje uspešna rekanalizacija krvnog suda nego što je to slučaj u odsustvu hiperglikemije $[6,10]$. Takođe, kod obolelih od šećerne bolesti češće se pojavljuje tranzitorni ishemijski atak (TIA), a češći je i moždani udar nakon tranzitornog ishemijskog ataka [11].

Dobijeni rezultati mogu se objasniti patofiziološkim mehanizmom nastanka moždanog udara $\mathrm{u}$ prisustvu diabetes mellitus-a. Kod obolelih od šećerne bolesti zapaženo je postojanje povećane agregacije trombocita, povećane produkcije faktora koagulacije VII i VIII i von Willebrand faktora, tromboksana A2 i tromboksana III, smanjene produkcije tkivnog aktivatora plazminogena, stanja hiperkoagulabilnosti i smanjenja fibrinolitičke aktivnosti. Povećana agregacija trombocita uslovljena je povećanim odgovorom trombocita na dejstvo adenozin-difosfata (ADP). U normalnim okolnostima, insulin smanjuje senzitivnost trombocita na ADP, ali kod šećerne bolesti reakcija trombocita je izmenjena. Zbog toga je češći slučaj da moždani udar nastane kao rezultat ishemije nego kao rezultat hemoragije $[6,10]$. Pojedina istraživanja su pokazala da je šećerna bolest 
udružena sa angiografski evidentnom okluzijom ekstrakranijalne karotidne arterije i bazilarne arterije [6, 12], kao i da je karotidna stenoza povezana sa povišenim vrednostima glikoziliranog hemoglobina i sa pozitivnim testom oralnog opterećenja glukozom $[6,13]$ i češća kod tipa 2 šećerne bolesti nego kod tipa 1 [6]. Takođe, kod obolelih od šećerne bolesti, pogotovu kod dugog trajanja bolesti i neregulisane hiperglikemije, javlja se zadebljanje medije i intime karotidnih arterija, što opet dovodi do suženja lumena karotidne arterije $[6,14]$. Sva navedena patološka stanja u prisustvu osnovne bolesti mogu dovesti do pojave komplikacija osnovnog oboljenja ili pridruženih bolesti, a što doprinosi da oporavak od moždanog udara bude sporiji nego što bi bio u odsustvu ovih patoloških stanja.

U našem radu pokazana je značajna razlika između vrednosti FIM skora na kraju procesa rehabilitacije i vrednosti FIM skora na njegovom početku, što pokazuje da je funkcionalni status pacijenata u toku rehabilitacije znatno poboljšan, odnosno da je rehabilitacija uspešno izvedena. Rezulati ovog istraživanja pokazali su da je funkcionalni oporavak obolelih, izražen razlikom u vrednosti FIM skora na kraju i na početku rehabilitacije, značajno bolji kod obolelih od tipa 2 šećerne bolesti u odnosu na obolele od tipa 1 šećerne bolesti. Uzrok ovakvog rezultata je u većem broju komplikacija nastalih usled dužeg trajanja bolesti kod obolelih od tipa 1 šećerne bolesti, tako da se pretpostavlja da one mogu usporiti proces rehabilitacije obolelih koji su preživeli moždani udar.

Rezultati ovog istraživanja nisu pokazali da diabetes mellitus kao komorbiditet ima uticaj na ishod rehabilitacije bolesnika koji su doživeli moždani udar. Ovakav rezultat odgovara rezultatima sličnih istraživanja $[7,15,16]$, koja potvrđuju zanemarljiv uticaj šećerne bolesti na funkcionalni oporavak obolelih sa moždanim udarom. Međutim, pretpostavlja se da je dobijenom rezultatu u ovom istraživanju doprinela činjenica da je izuzetno mali broj ispitanika uključen u istraživanje. Stoga, ovaj rad treba da predstavlja mali doprinos budućim istraživanjima na datu temu, u koje će biti uključen veći broj pacijenata, kako bi dobijeni rezulati bili što relevantniji i reprezentativniji. Takođe, buduća istraživanja treba da se usmere i na proučavanje uticaja posebnih tipova šećerne bolesti i nedijagnostikovane šećerne bolesti na funkcionalni oporavak pacijenata obolelih od moždanog udara [15].

Možemo zaključiti da diabetes mellitus kao komorbiditet, ne utiče značajno na ishod rehabilitacije pacijenata koji su doživeli moždani udar.

\section{Literatura}

1. Wang Q, Gao C, et al. Ischemic stroke hospital admission associated with ambient temperature in Jinan, China. PLoS One 2013; 8;11: e80381.

2. Joseph C, Rhoda A. Activity limitations and factors influencing functional outcome of patients with stroke following rehabilitation at a specialised facility in the Western Cape. Afr Health Sci 2013; 13;3: 646-654.

3. Barzel A, Ketels $G$ et al. Enhancing activities of daily living of chronic stroke patients in primary health care by modified constraint-induced movement therapy (HOMECIMT): study protocol for a cluster randomized controlled trial. Trials 2013; 14:334.

4. Shindo A, Tomimoto H. Diabetes and ischemic stroke. Brain Nerve 2014; 66;2: 107-19.

5. Luitse M, Biessels G, Rutten G Diabetes, hyperglycaemia and acute ischaemic stroke. The Lancet neurology 2012; 11;3: 261-271.

6. Baird T, Parsons M, et al. The influence of diabetes mellitus and hyperglycemia on stroke incidence and outcome. Journal of clinical neuroscience 2002; 9;6: 618-626.

7. Kwolek A, Wieliczko E. Rehabilitation after stroke in patients with diabetes mellitus. Neurol Neurochir Pol. 2000; 34;1: 49-60.

8. Young Y, Fan MY, et al. Concurrent Validity of Administering the Functional Independence Measure $\left(\mathrm{FIM}^{\mathrm{TN}}\right)$ Instrument by Interview. Am J Phys Med Rehabil. 2009; 88;9: 766-770.

9. Graham JE, Ripsin CM, et al. Relationship Between Diabetes Codes That Affect Medicare Reimbursement (Tier Comorbidities) and Outcomes in Stroke Rehabilitation. Archives of Physical Medicine and Rehabilitation 2009; 90; 7: 1110-1116.

10. Kissela BM, Khoury J, et al. Epidemiology of ischemic stroke in patients with diabetes: the Greater Cincinnati/ Northern Kentucky Stroke Study. Diabetes Care 2005; 28:355-359.

11. Hillen T, Coshall C, et al. Cause of stroke recurrence is multifactorial: patterns, risk factors, and outcomes of stroke recurrence in the South London Stroke Register. Stroke 2003; 34:1457-1463.

12. Bogousslavsky J, Regli F, Van Melle G. Risk factors and concomitants of internal carotid artery occlusion or stenosis. Arch Neurol 1985; 42:864-867.

13. Beks PHJ, Mackaay AJC, et al. Carotid artery stenosis is related to blood glucose level in an elderly Caucasian population: the Hoorn study. Diabetologia 1997; 24:290-298.

14. Wagenknecht LE, D’Agostino R Jr, et al. Duration of diabetes and carotid wall thickness: the Insulin Resistance Atherosclerosis Study (IRAS). Stroke 1997; 28:999-1005.

15. Ripley DL, Seel RT, et al. The impact of diabetes mellitus on stroke acute rehabilitation outcomes. Am J Phys Med Rehabil. 2007; 86(9):754-761.

16. Mizrahi EH, Fleissig Y, et al. Functional outcome of ischemic stroke: a comparative study of diabetic and nondiabetic patients. Disabil Rehabil. 2007; 29;14: 1091-1095. 